\title{
Sports Stars as a Means of Brand Communication in Côte d'Ivoire
}

\author{
Ouattara Katia \\ Université Peleforo Gon Coulibaly (UPGC), Korhogo, Côte d’Ivoire
}

\begin{abstract}
The growing interest of Ivorian companies in sports celebrities has led us to conduct research on sports stars as a means of brand communication in Côte d'Ivoire. This work, based on a semiological reading, reveals several persuasive strategies used by advertisers to seduce consumers: The use of sports celebrities as spokespersons for brands and above all as promoters of products because of their youth, elegance, and notoriety. These promotions are most often made from the competition areas where they work. Due to the low literacy level of the population, we are witnessing the use of simple language, etc.
\end{abstract}

Keywords: communication, sports star, advertising, media, semiology

\section{Introduction}

Advertising is one of the most widely used communication tools in our societies. On television, on the Internet or in the city, people are constantly solicited by advertising spots or posters. Through this means of communication, brands seek to influence consumers in order to sell their product or service. Over the past decade in Côte d'Ivoire, there has been an increasing use of sports celebrities as a means of attracting target audiences. Thus, it seemed relevant to us, through the advertising posters, to look at the use of these personalities designated as "individuals who are known to the public and who use this recognition to promote a product by appearing with it in an advertisement” (McCracken, 1989, as cited in Korchia \& Fleck-Dousteyssier, 2006, p. ?). This reality leads us to the following questions: What are the persuasive strategies used, through sports stars, to seduce Ivorian consumers? And what are the messages that come out of it?

The methodology used for this study is semiology, which is essentially based on Roland Barthes' binary model (denotation and connotation) quoted by Adam and Bonhomme (2014, p. 285), as applied by him in the analysis of Panzani spaghetti advertising. Barthes distinguishes three types of signs present in the advertising image: iconic signs (the image), plastic signs (aesthetic dimension), and linguistic signs (everything that comes under written words). In concrete terms, it is a question of enumerating, from each of these three signs, what we see and interpreting their various meanings.

The corpus is composed of eight randomly selected advertising posters. For example, the Burkinabe star Aristide Bancé, which is rarely used in advertising in Côte d'Ivoire, had his poster selected for this study. As for the other images, they concern those of Ivorian sports stars who are generally the most solicited in advertisements. These posters were analyzed to identify persuasive strategies and underlying messages.

Ouattara Katia, Ph.D., Teacher; Researcher; Assistant, Department of Information and Communication Sciences, Université Peleforo Gon Coulibaly (UPGC), Korhogo, Côte d'Ivoire. 
The various images to be examined are part of the exploitation of sponsorship contracts between Ivorian brands and international stars.

\section{The Relationship Between Orange and the National Football Team}

We start with two posters linking Orange Côte d'Ivoire to three leaders of the national football team.

\section{Didier Drogba, Aruna Dindané, and Kolo Touré at the Service of Orange Brand}

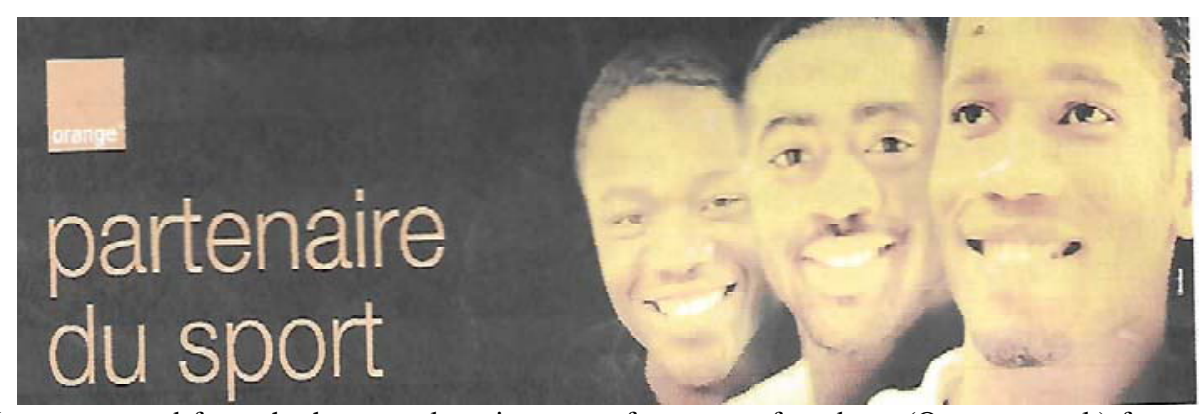

Figure 1. Image scanned from the homework assignment of a group of students (Ouattara et al.) from the Master's year (2008-2009), Department of Communication, Félix Houphouët-Boigny University, Côte d’Ivoire.

Iconic signs. From right to left, side by side, we see three players of the national football team (2004-2012): Didier Drogba, Kolo Touré, and Aruna Dindané. They have smiling faces. From an iconic point of view, these images remind us of the happiness they shared, of the team spirit that prevailed and that allowed the Ivorian team to be one of the most important on the continent (3rd African) and to be ranked among the best in the world (24/100) ${ }^{1}$ at that time (2008).

Plastic signs. Didier Drogba, Kolo Touré, and Aruna Dindané are in close-up. It is about putting the emphasis on the faces of happy players. In addition, in order of importance, Didier Drogba, then Kolo Touré, and finally Aruna Dindané comes. This is not due to chance. Indeed, at that time, Aruna Dindané played for Lens $^{2}$ (2005-2009), which is a smaller club than Kolo Touré's (Arsenal ${ }^{3}:$ 2002-2009), who in turn played for a sports organizationless important than Didier Drogba (Chelsea: 2004-2012). There is, here, a desire on the part of the advertiser to consider this reality at the photographic level. It is therefore the concern for truth that inhabits this one. The message is therefore clear: The company always keeps the promises made to its customers and partners.

At the level of the frame, it is rectangular in shape and has a black background. Inside it, we find the visual identity of the Orange brand, which is orange-white in colour and square in shape. The rectangle refers to the dynamism of the company while the square shape refers to stability. It thus promises its customers that it will never disappear, as some firms do, so as not to force them to change operators.

Linguistic signs. On the linguistic level, in the catchphrase: "Partner of sport", the subject and verb are missing. This catchphrase is therefore an elliptical sentence and this is not fortuitous. The omission of one or more words is used to emphasize what is mentioned. In this case, the point here, through the catchphrase, is to highlight the sponsorship that exists between this company and the Ivorian sport. From the logo, from top to bottom, you can read "Orange partner in sport". We can also read: "Orange partner of sport because it sponsors

\footnotetext{
${ }^{1}$ Source: http://www.rewmi.com/classement-fifa-2008-les-lions-reculent-encore-de-trois-places_a8388.html.

2 Lens is a French club; it currently plays in the second division league.

3 The Chelsea and Arsenal clubs belong to the English first division league. Chelsea has a more important record than Arsenal, as they won a Champions League in 2015, for example.
} 
the players Aruna Dindané, Kolo Touré, and Didier Drogba”. Orange Côte d'Ivoire states that it is the sponsor of the national football team. Therefore, we are dealing here with a synecdoche, since it uses a part of the players to design the entire national team. It is also an exaggeration because it generalizes its support for the Ivorian sport, only from these three players. The objective is to make the population sensitive to the issue of sport, and believe that it sponsors all the sports disciplines in Côte d'Ivoire. By showing that it is a socially responsible company that supports sport and its development, there is the hope of creating a sympathy that will have the effect of influencing the purchase. This social responsibility is a response to public expectations, because, as Bigle and Roskis (1996, p. 27) pointed out, the public wants companies "to take initiatives and, more generally, to participate in social life beyond their tasks as producers and traders”. Given the Ivorians' attachment to their national team, the help of companies can therefore meet this demand from the sports audience.

In 2013, the contracts between Orange Côte d'Ivoire and the players Kolo Touré and Aruna Dindané could not be renewed due to disagreement over the amount to be bound by the parties. Didier Drogba's has been renewed to this day. Thus, as part of the exploitation of this contract, at the entrance to each major city of Côte d'Ivoire, there is a player's advertising poster to welcome visitors or to say goodbye to those who travel. We reproduce the one concerning Korhogo, the city where we work.

\section{Didier Drogba, Spokesperson for Orange Côte d'Ivoire}

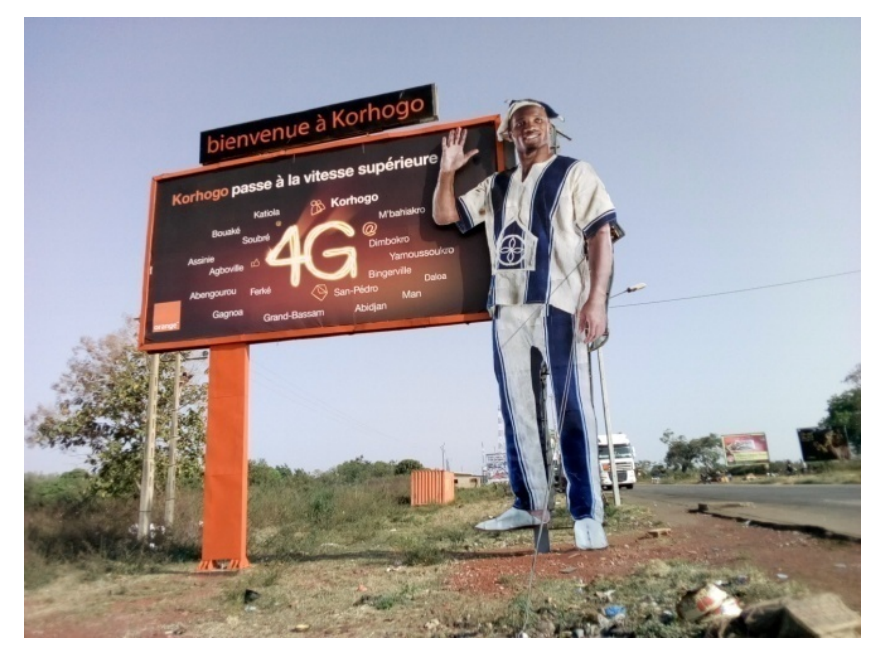

Figure 2. Photo taken at the entrance of the city of Korhogo on 23/11/2018.

Iconic signs. At the iconic level, we can see Didier Drogba dressed in traditional white and blue senoufo ${ }^{4}$ outfits and wearing a pair of white slippers. He has a smiling face and a raised right hand as a greeting. The player's image overflows the poster because he stands on the ground and his limit at the top (the head) slightly exceeds the poster. On the pocket of this outfit, we see a butterfly. Blé (2012, p. 3) also pointed out in this regard that "the senoufo loincloths are decorated with many animals". Didier Drogba, from the Bété ethnic group, is dressed in traditional northern clothing to welcome those entering the city of Korhogo. This reality can make people smile, but as De Barnier and Joanis (2016, p. 291) pointed out, laughter can be effective because "it is a sure factor of attention". This attention process (humour) is reinforced by the large size of the

\footnotetext{
${ }^{4}$ Senoufo is an ethnic group located in northern Côte d'Ivoire in the regions of Poro, Tchologo, Bagoué, and Hambol.

5 This ethnic group is located in the west of Côte d'Ivoire, precisely in the regions of Gôh, Haut-Sassandra, and Nawa.
} 
player and the unusual nature of such a poster. It is therefore difficult not to see it at the entrance to the city of Korhogo. The advertiser can thus deliver his message.

The butterfly on the player's clothing refers to the movements of the hunter in search of game. It also refers to the theme of travel, that is to say, those who leave or enter the city of Korhogo. As far as colours are concerned, Pastoureau and Simonnet (2007), authors of the "Petit livre des couleurs" quoted by Atchoua (2013, p. 221), reveal that: "white colour denotes purity, delicacy, unity and peace”. From these words, it is clear that the Senufo people are a people of peace and unity. It is also a people of faith rooted not only in ancestral values (animism) but also in the Muslim religion and this from the shoes worn by Didier Drogba. This religious faith is reinforced by the colour blue, which refers to the sky and thus to the recognition of the existence of a supreme being. The star, by this dress, affirms that he shares the religious faith and traditional values of the Senufo people. This way of doing things establishes a strong link with this population that has always supported it ${ }^{6}$.

Plastic signs. From the plastic point of view, we have Didier Drogba in the foreground and in the background; we have the advertising poster written in a rectangular frame with a red border. Just above the poster, we have a small rectangular frame. The two rectangular frames refer to the dynamism of the player and the advertiser. As for the small square frame with an orange background, inside the large rectangular frame, it refers to Orange Côte d'Ivoire. It is therefore this company that, through Drogba, welcomes those who enter the city.

The emphasis on the athlete is a process to draw the attention of travellers to the athlete. The red colour that borders the rectangular frame of the poster refers to Drogba's attachment and therefore the brand's attachment to the Senufo people. The orange colour of the logo is reminiscent of the Orange Group's business: communication, that is to say, fixed, mobile, and Internet telephony.

Linguistic signs. In the small rectangular box, it says "Welcome to Korhogo", which is in keeping with Drogba's image of waving his hand at the entrance to the city. There is a contraction of the subject and the verb in this sentence. This shows the advertiser's desire to provide a quick reading for travellers who are very often on the move by motorcycle or car.

By putting the name of the city in Orange, the company informs us that the city's exchanges are made through the Orange network. From the sentence "Korhogo is moving up a gear", we understand that the municipality has the most efficient communication network. The Internet symbols on the advertising poster around 4G: An envelope representing the emails, a thumb referring to a Facebook like, and the two guys expressing an instant discussion, show us that this is about promoting the company's Internet network. The 4G that is inscribed in the centre of the poster means that the advertiser has, like other global mobile brands, integrated the fourth generation of wireless technology. This network, based on the white color of the verbal group, is pure. Considering that there is a Didier Drogba poster at the entrance of every major city in Côte d'Ivoire, we can say that the satisfied player of the Orange group invites these many fans, across the country, to imitate him by joining the brand.

\section{MTN Côte d'Ivoire’s Reaction: Gervinho and Murielle Ahouré as Brand Ambassadors}

In this marketing war between mobile phone companies to win the favour of the Ivorian public, MTN chose Yao Kouassi Gervais (Gervinho), one of the leaders of the national football team and Murielle Ahouré,

\footnotetext{
${ }^{6}$ Direct observation makes it possible to highlight the mobilization of the population in front of the television sets of the coffee kiosks or in the sales areas of household appliances during Didier Drogba's matches with the various clubs with which he played. We have even often heard that when Didier Drogba plays, Côte d'Ivoire plays.
} 
the world's leading athletics star. We will successively analyze two posters of these sports stars. We start with Gervinho.

\section{MTN Picks up in the Elephant Footballers}

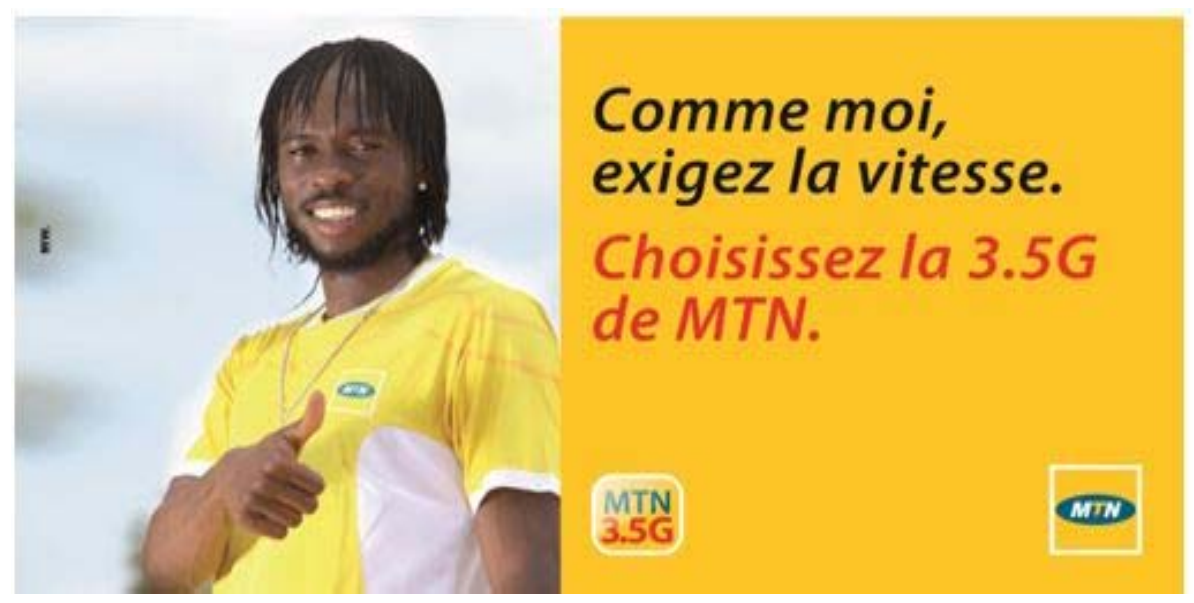

Figure 3. Image received from MTN Côte d’Ivoire.

Iconic signs. In the picture on the left, we see Gervinho smiling and waving with his right thumb. The latter wears a yellow, white, and blue T-shirt with a predominance of yellow.

Gervinho is happy and this happiness is related to the outfit he wears. If the orange and white colours are reminiscent of the Orange group, the yellow, white, and blue colours are reminiscent of the MTN brand. Gervinho's happiness, through the advertising poster, comes from MTN, whose T-shirt he proudly wears. The thumb sign reinforces the idea that with MTN you are satisfied. We know that the yellow colour refers to joy, which is very much in line with the player's smile. Gervinho invites all those who want to become like him to join MTN.

Plastic signs. At this level, Gervinho is in a close-up shot. The poster is rectangular in shape and divided into two parts: a vertical frame (left) with a light blue background and a horizontal frame with a yellow background. On the right side, at the bottom, at the end, there is a square with a yellow background and a white border.

The close-up shot is used to emphasize the player's smile, gesture, and clothing. This composition informs us that the MTN group is a firm that provides satisfaction to its clients. The vertical frame refers to the movements, those of Gervinho on the field of play which are characterized by speed. These movements also refer to the MTN network which, from Gervinho, has a high navigation rate. Customers can therefore exchange under optimal conditions. The horizontal frame expresses the serenity of the MTN group in the face of competition. The rectangular shape of the poster confirms the dynamism of this brand.

The poster therefore establishes a logical link between the player's speed (left) and the MTN brand. This brings us back to the phenomenon of congruence, that is, the perceived similarity between a partner and a sponsored entity. On this issue, authors such as Misra and Beatty (1990), Kamins and Gupta (1994), and Lunch and Schuler (1994) quoted by Korchia and Fleck-Dousteyssier (2006) note that the more logical the link is, the more impact it has on the brand. This is why they state: "the more the celebrity/brand couple is perceived as adapted, relevant or congruent, the more positive the response to advertising will be in terms of attitude or purchase intent”. Thus, unlike Orange Côte d'Ivoire, which has focused on the attachment of the population to 
Didier Drogba and the convocation of culture as a means of seducing the population, MTN has preferred to highlight the very strong link that exists between the characteristics of Gervinho (speed) and the speed of navigation of its network.

Linguistic signs. As for the text, the catchphrase "As I, require speed” is written in black while the subtitle "Choose MTN's 3.5 G" is in red. Still at the level of the catchphrase, there is not only a comparison "like me" but also an imperative "demand speed".

Being considered one of the fastest players in the world, Gervinho has chosen an Internet network that suits him perfectly. For this sports star, consumers must be demanding in making the choice for the MTN brand. The subtitle of the article confirms what we say: “Choose MTN's 3.5 G”.

From the black color, we can say that the player wants to speak truth to Ivorian consumers: MTN has the highest Internet browsing speed. The red colour of the subtitle refers to the emotional attachment that Gervinho has for the MTN network because of its performance. The player is the authority on speed. He can therefore give advice on this aspect, hence the use of two mandatory sentences. It is this credibility that the MTN brand uses to seduce consumers.

To consolidate the network's image of speed, MTN also called on Murielle Ahouré.

\section{Murielle Ahouré and MTN: Strengthening the Broadband Image of the Internet Network}

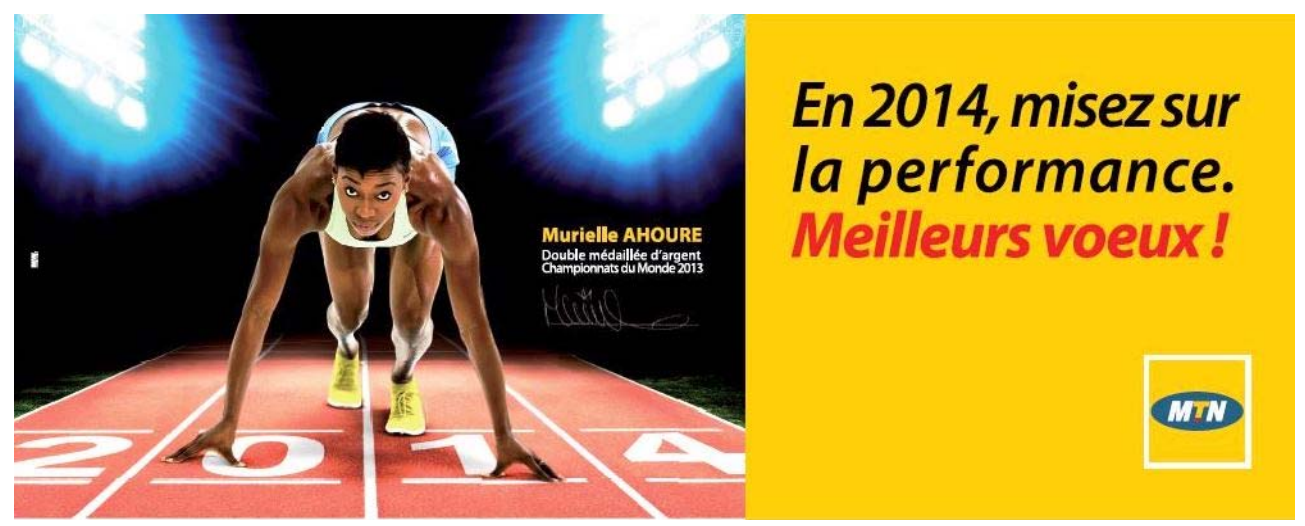

Figure 4. Image received from MTN Côte d’Ivoire.

Iconic signs. Murielle Ahouré is lowered into the starting position on a red track. It is delimited by white lines. The world's leading athletics star is dressed in a yellow T-shirt, a blue-white shirt, and a pair of yellow crepe. She looks serenely forward while waiting for the start signal. The blue, yellow, and white colours are those of MTN. She is therefore the representative of this brand on the athletics track. She is alone because as runner-up in the world, there is no other athlete who can compete with her in Africa and Côte d'Ivoire in 2014. Thus, through Murielle Ahouré, the message is clear: In terms of communication speed, the company is second in the world and leader in Africa. The red colour of the track refers to the athlete's dynamism and performance and therefore to that of the sponsoring brand. The white color that recalls the MTN group refers to the purity of the Internet network.

Plastic signs. The poster is rectangular in shape and divided into two horizontal frames: The one on the left with Murielle Ahouré's image, while the one on the right has a yellow background. In the left horizontal frame, Murielle Ahouré is in the foreground and in the background, we have two projectors set in a black background and emitting white and blue colors. 
The black background refers to the night, hence the illumination of the projectors. It is also a desire to highlight the world's leading athletics star. This reality is reinforced from the point of view of composition because the athlete is put in the foreground. The horizontal frame is generally used to indicate calm and tranquility. This is consistent when you look at Murielle Ahouré's face, which, in her favourite field, radiates confidence, conviction, and serenity. Through this celebrity, MTN insists on its serenity in the face of competition. As for the second yellow background frame, it symbolizes the MTN brand. As a result of the above, what linguistic decoding is needed to produce meaning?

Linguistic signs. In the catchphrase "In 2014 focus on performance", it can be noted that the title is written in black while the subtitle "best wishes" is in red. At the bottom, in the square frame, we can see MTN in white, yellow, and red. In the athlete's frame, it is easy to read, in yellow, "Murielle Ahouré" and just below, in white, “double silver medal, 2013 world championship”.

The catchphrase places us in the year of the development of this advertising poster. We are at the beginning of 2014. The world star recommends that we focus on performance in that year. This tagline, which is written in a yellow background, clearly shows that Murielle Ahouré refers to MTN as the Internet network with the highest browsing speed. The logo confirms what we are saying. From the black colour of the hook, the sports star informs us that these are not untruths.

Through Murielle Ahouré, MTN, on the occasion of the New Year, wishes its best wishes to the population to whom it claims to be deeply attached (red color of the tagline). She shows him her attention. The brand also tells him that, like this athletics star, it has the most efficient Internet network on the market. MTN therefore invites Ivorians to choose its company.

The Société des Limonaderies et Brasseries d'Afrique (SOLIBRA) has also used sports celebrities, which is what we will see in the following lines by making a semiological reading of one of its posters.

\section{Drogba at the Rescue of SOLIBRA}

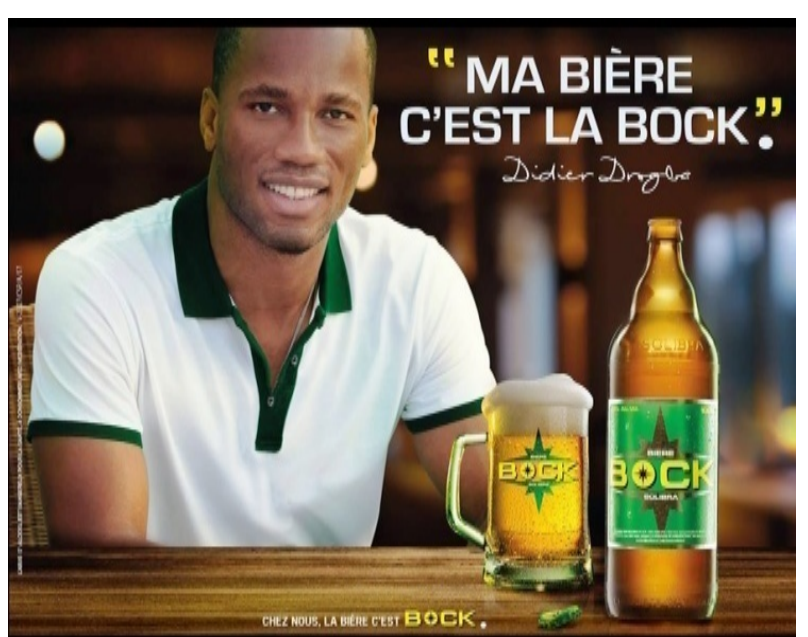

Figure 5. Image taken from Konan Sylvain's article in the journal Strat'Marque. (Source: https://stratmarques.com/d-drogba-maillot-de-solibra-y-a-beaucoup-a-dire/).

\section{Iconic Signs}

In the picture, we can see the Ivorian football star, Didier Drogba sitting and smiling. In front of him, on the table, there is a bottle and a glass containing beer. This means that the player's smile comes from drinking 
the drink in front of him. The absorption of this beverage is therefore a source of happiness for those who drink it.

This beer is yellow in colour in the glass as if to justify the richness of its content. The stars on the packaging of the glass and bottle reveal the feeling of belonging: It is the beer of the stars. This reality is also in line with the status of Didier Drogba, who is a global star.

If the star on the beer glass is green, the star on the bottle packaging is brown. The packaging of the bottle is green. The color green is the color of luck and hope. It is therefore a drink that provides fortune, hence the possibility of becoming like Didier Drogba (success and wealth). It is also the colour of nature and youth. This beverage therefore gives a feeling of youthfulness and internal well-being. The brown colour refers to the earth, that of Côte d'Ivoire. We are therefore dealing with a local beer rooted in the Ivorian territory, which gives off a scent of authenticity.

Following the iconic signs, according to Barthes, the question of plastic signs must be addressed.

\section{Plastic Signs}

Didier Drogba is located in the background, in the close-up chest, while the beer is in the foreground, in the close-up. By the close-up chest shot, the announcer wants to focus on the upper part of the former Chelsea player. The latter is dressed in an outfit that reflects the advertiser's colours (SOLIBRA). The player's face shows how happy he is to drink the beer in front of him. The close-up on the product in the foreground indicates the advertiser's willingness to actually communicate on his product. This is what Barnier and Joannis (2016, p. 128) called the qualified product, which "consists in placing one or more elements near the products that will add a dimension that is missing from its simple representation”. Inside the glass, there is a white foam like Didier Drogba's T-shirt. The collar and sleeve ends are green like the packaging of beer and the star of the glass containing this drink. Moreover, the stars on the glass and the beer bottle perfectly refer to Didier Drogba who is a star, that is to say, a planetary star. There is therefore a strong congruence between Didier Drogba and the beer he drinks. This very strong link shows the advertiser's willingness to reflect the player's real attachment to this drink. This gives it a new dimension. From the beer of those with few means ${ }^{7}$, it becomes the drink of celebrities.

\section{Linguistic Signs}

The catchphrase "My beer is the bock" is located not far from Didier Drogba's face. This means that this statement is indeed from the former Chelsea player whose signature at the bottom of the tagline confirms his statement. The bock is a star beer just like Didier Drogba is. The player has therefore chosen a drink that fits strongly with his personality and social class.

It should be noted that since the arrival of Ivory beer ${ }^{8}$ on the market in November 2016, Bock has seen a drop in its sales. This reality explains Didier Drogba's choice as ambassador for this brand given its attractiveness to the population. This option is also justified by the fact that for some years now, Ivorians have been calling big beer: Drogba beer. When ordering drinks in bars, for example, you can even hear customers say "give me a Drogba". To exploit this opportunity, the brand has therefore chosen to sign a partnership agreement with the player.

\footnotetext{
${ }^{7}$ Bock beer $(100 \mathrm{cl})$ is also called family beer or big beer because of its shape. It is seen in Côte d'Ivoire as the beer of those who have few resources. Ordering this drink in certain areas can cause surprise or mockery. A large beer allows a large number of individuals to share the content. Next to this format, there is the $66 \mathrm{cl}$ bock and the $33 \mathrm{cl}$ one called bockette.

${ }^{8}$ This beer belongs to Heineken, a Dutch group, which has broken the monopoly held by SOLIBRA for more than 60 years, belonging to the French group Castel.
} 
Salomon Kalou, like Didier Drogba, is one of the sports stars used by advertisers in Côte d'Ivoire. We will now analyze one of the advertising posters that concerns this personality.

\section{Salomon Kalou (Kaluno) Spokesperson for Smart Techonology Brand}

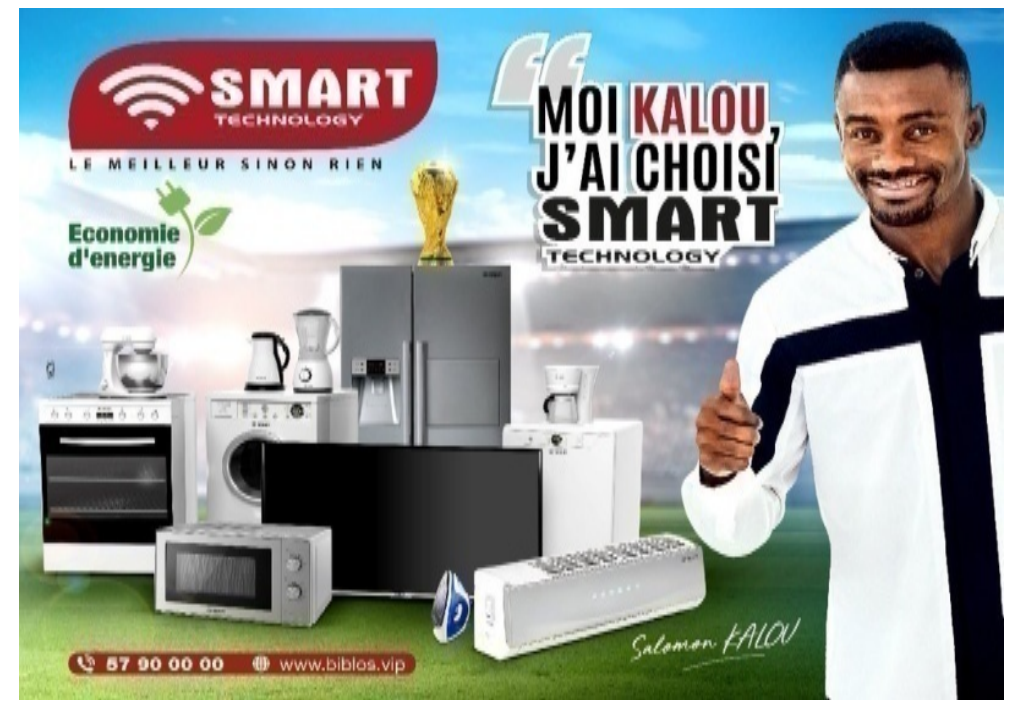

Figure 6. Image received from Smart Technology (Source: https://images.app.googl/Px9DcN6YUfy.ntHsk7).

\section{Iconic Signs}

At the iconic level, we see Kaluno smiling, dressed in a white and black shirt. This one, with his right thumb up, waved. Behind it, there are household appliances, such as gas cookers, televisions, air conditioners, refrigerators, etc. This equipment is placed on a playing surface in a stadium where you can see the green lawn.

Like Kaluno, the household appliances are white and black, with grey added. The player is telling us that if he is happy and has so much performance on the itch $^{9}$, it is thanks to all these products that we see on the advertising poster. Moreover, the presence of the 2015 African Cup of Nations (CAN) football trophy on the poster confirms our point.

Black is the colour of elegance, beauty, and class. This reality fits well with that of Salomon Kalou. Indeed, he is a handsome man, rich and elegantly dressed. The household appliances he uses are therefore those of a certain social class. The white colour refers to cleanliness, which means that the products on offer are of high quality, which corresponds to Salomon Kalou's elegance and status. The grey colour is also that of elegance, which shows its redundancy in the poster, thus reinforcing what we have just said.

\section{Plastic Signs}

In the image, Kaluno is in close-up view. The player is also in the foreground and in the background we have the advertiser's products and a stand. We can say, from the close-up shot, the willingness of the advertiser to emphasize the elegance of the player, his beauty and the happiness he experiences. It is highlighted here because it is the main element of the poster from which the message can be delivered and perceived.

The platform we see in the background refers to the Ivorian sports audience. The athlete is therefore in the middle of the stadium and addressing his fans. Here, it should be noted that there is an unexpected, unusual

\footnotetext{
${ }^{9}$ Salomon Kalou is the winner of the African Cup of Nations (CAN) 2015, the best hopeful of the 2005 Dutch league, and the UEFA Champions League winner in 2012 with Chelsea. With the same team, he was England champion (2010) and winner of the 2007, 2009, 2010, 2012 English Cup, etc.
} 
reference because the products are supposed to be presented in appropriate spaces: shops, exhibitions, and fairs. The products are found on a football field, Salomon Kalou's favourite place. This can be a source of surprise, which makes it easier to remember the message. Our position is based on Cadet, Charles, and Galus (2006, p. 115) for whom surprise is a process that "facilitates memorization". However, as Petre (2005) and Walliser (2006) quoted by Smaoui and Choura-Abiba (2008, p. 5) noted, "memory occupies a central place in the study of consumer behaviour and considerably influences its decision-making process”. For the last two authors cited, it is this reality that explains the interest of advertisers in reputation studies (spontaneous and assisted) because they make it possible to verify the presence of the brand in the minds of customers. Apart from the surprise, it should be noted that this unexpected reference can also provoke a smile, which is an effective way to attract attention.

\section{Linguistic Signs}

The catchphrase "I Kalou I chose Smart Technology" is a simple sentence and can be easily understood by the reader. The player informs us that the happiness you can see on his face is due to the choice of Smart Technology. This company is therefore the brand of stars and elegant people. This is reinforced by the name of this firm which means chic, charming, and elegant. The brand has therefore chosen a personality that corresponds to its image. This is an identification strategy.

Salomon Kalou invites all those who value him and want to become like him to buy Smart Technology products. We are thus in projective advertising insofar as the act of purchase can be "a means of identification and social promotion” (Adam \& Bonhomme, 2014, p. 24). In addition to the advantages already mentioned, the world star informs us that with this company's products, energy savings are achieved, thus reducing waste.

While Smart Technology chose Kaluno, the New Inter-African Insurance Company (NSIA) Bank called on the Burkinabe sports star Aristide Bancé. We analyse the advertising poster in question in the following lines.

\section{The Association Aristide Bancé and NSIA Bank}

\section{Iconic Signs}

At the iconic level, we can see Aristide Bancé holding a ball in his hand on the lawn of Marcory Champroux Stadium ${ }^{10}$. One of the stands behind the player can be seen behind him in this sports area. The athlete is dressed in a yellow, black, and white jersey. On this outfit, you can recognize the NSIA bank logo. As for the balloon, it is made up of different colours. Around it, there is a green support.

The yellow, black, and white outfit is that of the ASEC Mimosas team, the player's club ${ }^{11}$. The different types of colours on the balloon represent the flag of different countries recognizable from the national colours. This balloon is therefore also a terrestrial globe which can be confirmed by the green support located around it.

By presenting us with the map of the world, this celebrity talks to us about his ambitions but also about those of the club (ASEC) and NSIA Bank, which is to conquer Côte d'Ivoire, Africa and the world. The NSIA brand on the player's jersey reflects the partnership between the player and this African brand. Taking into

\footnotetext{
${ }^{10}$ It is the second sports area where the national football championship of the first division of Côte d'Ivoire is held. Félix Houphouët-Boigny Stadium is the country's largest sports centre.

11 The Association Sportive des Employés de Commerce (ASEC) is one of the largest clubs in Côte d’Ivoire. Aristide Bancé played there during the 2016-2017 season when he finished as best player, top scorer and champion of Côte d'Ivoire.
} 
account the logos of some money transfer companies (WU, Ria) ${ }^{12}$ on the ball and on the jersey, we can say that the player invites his fans from all over the world to make their financial exchange through NSIA Bank which has all these different money transfer structures.

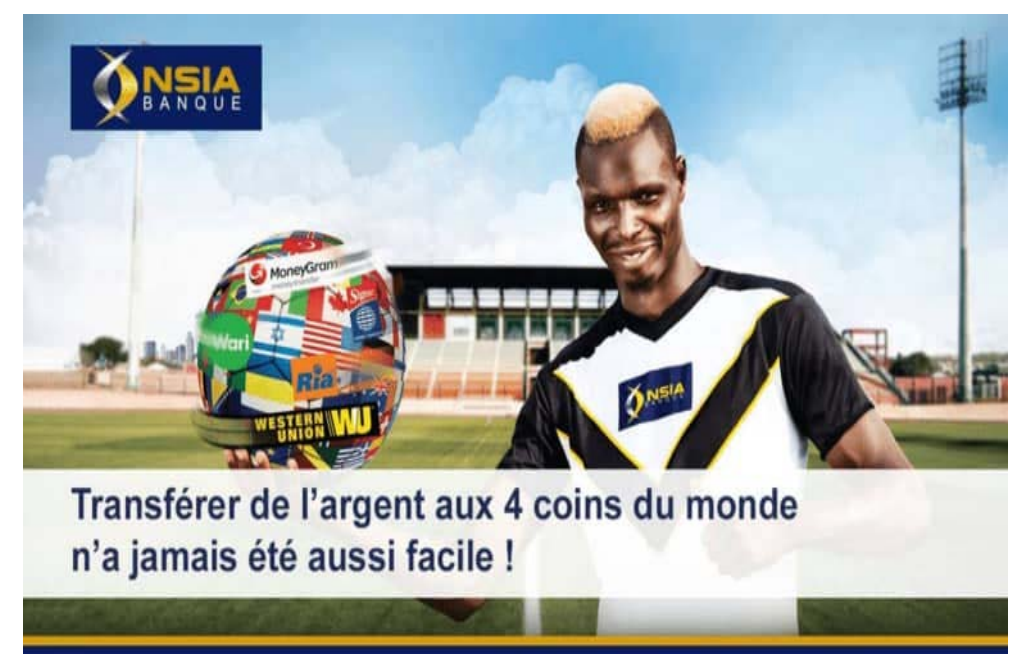

Figure 7. Image taken from Konan Sylvain's article in the le journal Strat'Marque.

(Source: https://stratmarques.com/campagne-nsia-banque-analysons-cette-tactique-bance/).

\section{Plastic Signs}

The Burkinabe athlete is in a close-up chest shot. The focus here is on the company logo and the player's face, which shows that he is happy with his partnership with the NSIA Bank brand.

Aristide Bancé is in the foreground holding in his hand a map of the world. In the background, we have Champroux Stadium in Marcory, then the supporters' gallery. Taking into account the composition of the elements, it can be said that this one is aimed at all its fans. In fact, he has played in more than 20 clubs around the world. Therefore, it is to those that it is addressed: Make your bank transfers through NSIA bank using Western Union, Ria, Money Gram. He tells them that in all the countries where he has spent his time as a player, he has always used NSIA Bank and that he has always been satisfied.

\section{Linguistic Signs}

The catchphrase "Transferring money to the four corners of the world has never been so easy" shows that it is a global money transfer, which is in line with what we have already said. As this is not easy, the bank intends to solve this problem. It therefore informs consumers that they can make any type of transfer to the globe via its structure. In this sense, it chose the international Burkinabe star who was born in Abidjan (Côte d'Ivoire) and who has played in several continents (Africa, Europe, and Asia) ${ }^{13}$. Through it, the brand bridges the gap between Côte d'Ivoire, Burkina Faso, the sub-region, Africa, and the world. In addition, it should be noted that Côte d'Ivoire has more than four million Burkinabés, which represents the largest foreign community. The player therefore makes recommendations to all these populations.

Following Aristide Bancé, we are completing the analysis of the advertising posters with Murielle Ahouré, spokesperson for the Cocoa Coffee Council.

\footnotetext{
12 They refer to Western Union and Ria Money Transfer respectively.

13 Aristide has played, for example, in Africa at ASEC Mimosas (Côte d’Ivoire: 2017), in Europe at RSC Lokeren (Belgium: 2003-2006) and in ASIA at FK Irtyh Pavlodar (Kazakhstan: 2015).
} 


\section{Murielle Ahouré Ambassador of the Cocoa Coffee Council}

\section{Iconic Signs}

At the iconic level, we see two images of Murielle Ahouré, one larger in which we can see the sprinter holding a chocolate bar and smiling. The other, more fuzzy, in which she is in sports clothing, is running on an athletics track. In front of the two images, we can see a cup filled with coffee, coffee beans, and chocolate bars. The shirt she wears is black with a yellow collar in which black and white can be found.

The colour black refers to the athlete's beauty and elegance. The yellow indicates the joy, reinforcing the pleasure and pride of this world-class athletics star, crunching chocolate from the cocoa of her native country.

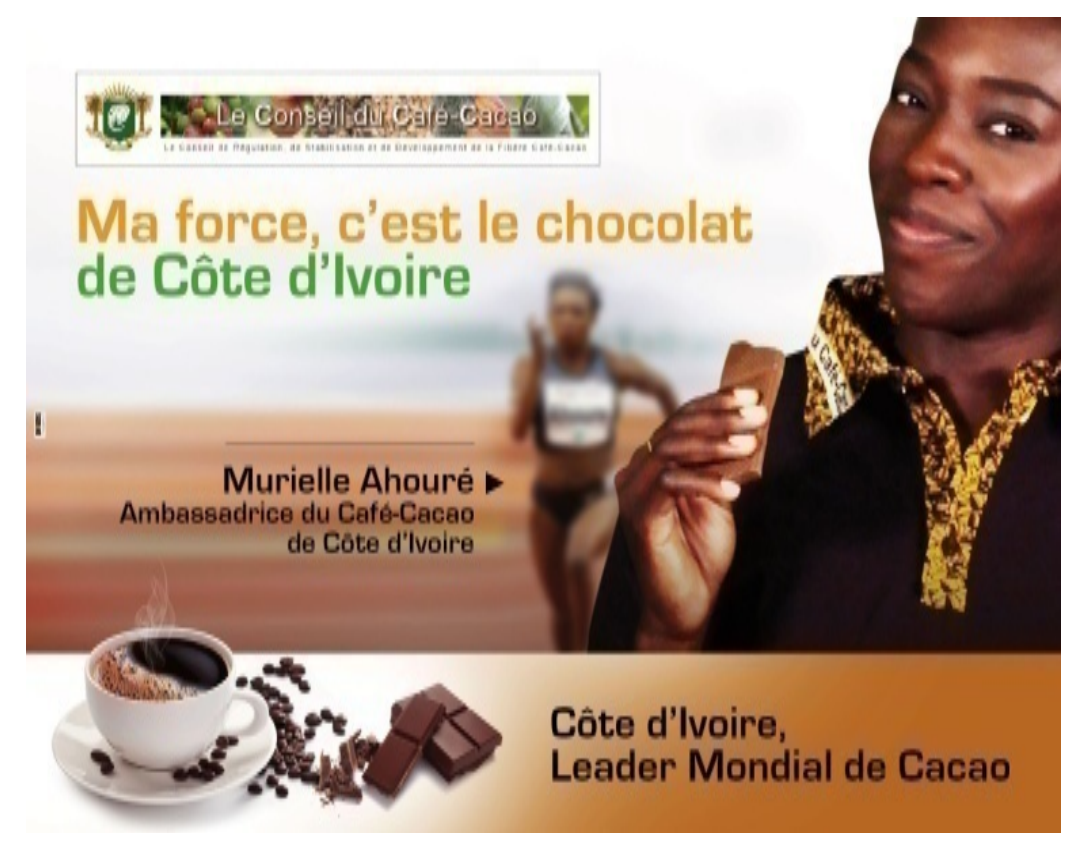

Figure 8. Image received from the Cocoa Coffee Council.

\section{Plastic Signs}

From the point of view of framing, Murielle Ahouré, in the first image is in a close-up chest shot. It is a question of emphasizing the beauty of the athlete's clothing and the happiness she feels when consuming chocolate. In the second image, the athlete is in the middle shot. Therefore, the photographer walked a little farther away to show us the athlete in action on an athletics track.

From the point of view of composition, the advertiser highlights a cup of coffee. In the background, we have a large image of Murielle Ahouré happy to eat chocolate and in the background we see her running on an athletics track. We understand that the happiness that can be seen on the athlete's face and the results obtained on the athletics track in Africa and around the world ${ }^{14}$ are the result of the consumption of cocoa and Ivorian coffee. Beyond that, it is therefore a question of encouraging foreign customers to buy these products made in Côte d'Ivoire. While Côte d'Ivoire is the world's largest producer of cocoa, it should be noted that national consumption is low. Murielle Ahouré's choice as ambassador is therefore also intended to increase local consumption.

\footnotetext{
${ }^{14}$ She was double world champion in 2013, African champion in 2014, world champion in 2018 and winner of the 2018 Women's Diamond League, etc.
} 


\section{Linguistic Signs}

On the linguistic level, the catchphrase "My strength is the chocolate of Côte d'Ivoire" completes the image and confirms our comments. The catchphrase written in orange and green in a white background shows Murielle Ahouré's attachment to Côte d'Ivoire.

The advertiser, through the athlete, addresses the customers. To those who consume Ivorian cocoa, she tells them that they have made the right choice like her. To potential consumers, it tells them to choose Ivorian cocoa because it has the best possible qualities in the world. Moreover, Côte d'Ivoire is recognized as the world leader in cocoa and the advertising poster was keen to highlight this. The advertiser behind this poster is the Cocoa Coffee Council, which is the structure responsible for marketing, regulating, stabilizing, and developing the coffee and cocoa sector. It is this organization that uses Murielle Ahouré as a means of communication and seduction of the national and global public. Indeed, given its importance, $\operatorname{cocoa}^{15}$ is a sovereign product in Côte d'Ivoire, hence the involvement of the Cocoa Coffee Council in its promotion with a view to improving the incomes of all stakeholders in the sector.

\section{Conclusion}

At the end of this analysis, what are the persuasive strategies used by brands and what are the messages? The study shows that brands use a variety of techniques to appeal to Ivorian consumers. There are above all the uses of the rectangular framework to reflect the dynamism of companies and the horizontal framing to show their serenity in relation to the competition. In terms of shot scales, it is the use of the chest close-up shot or the waist close-up shot to highlight the faces of sports stars and their elegance and beauty. In addition, it should be added that the products of companies are very often highlighted and highlighted by sports stars. The aim is to prove that the joy that can be seen on the faces of these personalities is linked to the use of the products of the sponsoring brands and thus to invite fans to imitate them.

As far as colours are concerned, there is an abundant use of yellow to enhance the happiness of sports stars. It is also about reporting on the energy provided by the products of these brands and therefore showing that the success of these celebrities is also linked to their use. There are also the colours white and red. The first is to explain the quality and purity of the products or services. The second is to show the deep attachment of sports stars to the people and therefore of sponsoring brands to them. Black is also used to reflect the elegance of the athletes and the sincerity of the messages of the companies and their spokespersons. This staging is reinforced by the very strong link between athletes' clothing and corporate products or services. In this sense, stars are very often dressed in the colours of the brands they promote. We also note the use of traditional culture to seduce local populations. In addition, the use of humour to provoke laughter or astonishment must be mentioned and a simple vocabulary chosen to facilitate the understanding of the messages. This reality is explained by the fact that Côte d'Ivoire has 56.1\% of illiterates according to the 2014 General Population and Housing Census (RGPH). This figure takes on much more worrying proportions when one moves away from the economic capital (Abidjan), especially in the north, where the illiteracy rate is over $70 \%$.

This research work has highlighted the strong competition between companies, particularly in the mobile telephony sector. Indeed, knowing the attachment of Ivorian populations to the national football team, the Orange brand has signed a sponsorship contract with the Ivoirian Federation of Football (FIF). She has also

\footnotetext{
${ }^{15}$ Côte d'Ivoire is the world's largest producer of cocoa, accounting for nearly $45 \%$ of world production.
} 
signed with nine players from this team, including Didier Drogba, Salomon Kalou, Kolo and Yaya Touré, etc. MTN, in order not to leave the field to its direct competitor, offered itself, in this selection, Yao Kouassi Gervais (Gervinho) and added Murielle Ahouré, the leader of the national athletics team. If this approach resembles a phenomenon of ambush marketing, one can nevertheless wonder what impact these two advertising posters (that of Didier Drogba and Gervinho) have on the Ivorian consumer.

\section{References}

Adam, J. M., \& Bonhomme, M. (2014). L'argumentation publicitaire (Advertising argumentation). Paris: Armand Colin.

Atchoua, N. J. (2013). Le pagne comme langage et média de mobilisation électorale en Afrique (The loincloth as language and média for electoral mobilization in Africa). Communication en Question, 2, 212-240.

Bigle, G., \& Roskis, D. (1996). Sponsoring: Le parrainage publicitaire (Sponsorship: Advertising sponsorship). Paris: Dalloz.

Blé, R. G. (2012). Le pagne un moyen de communication en Côte d'Ivoire (The lioncloth as communication means in Côte d'Ivoire). Retrieved from https://journals.openedition.org/communication/3026

Cadet, C., Charles, R., \& Galus, J. L. (2006). La communication par l'image (Communicattion through images). Paris: Nathan.

De Barnier, V., \& Joannis, H. (2016). Marketing et création publicitaire (Marketing and advertising design). Paris: Dunod.

Konan, S. (2017a). Campagne NSIA Banque: Analysons cette tactique Bance! (NSIA Banque campagne: Let’s analyse this Bance tactic!). Retrieved from https://stratmarques.com/campagne-nsia-banque-analysons-cette-tactique-bance

Konan, S. (2017b). D Drogba sous le maillot de Solibra, il y a beaucoup à dire (D Drogba in the Solibra's jersey, there's a lot to talk about). Retrieved from https://stratmarques.com/d-drogba-maillot-de-solibra-y-a-beaucoup-a-dire/

Korchia, M., \& Fleck-Dousteyssier, N. (2006). Les célébrités dans la publicité: Le rôle de la congruence (Célébrities in advertising: The rôle of congruence). Cahier: Centre de Recherche DMSP.

République de Côte d'Ivoire. (2016). La Côte d'Ivoire en chiffre (Côte d'Ivoire in figures). Abidjan: Dialogue Production.

Smaoui, F., \& Choura-Abida, F. (2008). Effet du type d'audience sur la mémorisation des sponsors: Cas de l'exposition de l'audience directe VS indirecte à un événement répétitif dans le temps: Le championnat de football tunisien (Effect of the type of audience on the memorisation of sponsors: Case of the exposure of the direct audience directe VS indirect to a repetitive event in time: the Tunisian football championship). Retrieved from http://www.docstor.com/docs/92649080/R\%2523\%25A9resultats 